\title{
ACTIVATED PALYGORSKITE AND ACTIVATED BENTONITE CLAY AS THE CATALYSTS OF THE PROCESS OF COOLIGOMERS OBTAINING FROM ETHYLENE PRODUCTIONS BYPRODUCTS
}

\author{
Lviv Polytechnic National University, \\ 12, St. Bandera str., 79013 Lviv, Ukraine; voronchak.taras@gmail.com
}

Received: J une 04, 2011 / Revised: J une 26, 2011 / Accepted: September 20, 2011

(C) Voronchak T., Nykulyshyn I., Pikh Z., Rypka A., 2012

\begin{abstract}
The cooligomers production using $\mathrm{C}_{9}$ fraction of diesel fuel pyrolysis liquid products in the presence of silica-alumina acid type catalysts: activated palygorskite and activated bentonite clay has been investigated. Dependences between process conditions and cooligomer yield as well as between conditions and cooligomer properties have been studied. The relation between the catalysts properties and results obtained in their presence has been analyzed. The catalysts comparative analysis has been carried out.
\end{abstract}

Keywords: liquid pyrolysis products, cooligomers, heterogeneous catalysts, palygorskite, bentonite clay.

\section{Introduction}

The fractions of liquid pyrolysis products utilization is an actual problem having both economical and ecological importance. Production of cooligomeric products, having a wide range of applications, from these fractions is the most reasonable way of their utilization. We propose a new method of cooligomers obtaining from the liquid pyrolysis products, based on using the acid type silica-alumina catalysts. These materials are capable to catalyze the process due to the presence of Brønsted active sites on their surface (Fig. 1) [1,2]:

Use of heterogeneous catalysts of such a type enables to avoid the neutralization and washing stages, being required in homogeneous catalysis, since the catalyst can be easily separated by filtering. Thus, a prob- lem of waste water is solved and a number of process stages decreases. These catalysts do not lose their activity when stored and do not create corrosion aggressive mediums. Besides, the cooligomers obtained by such a method have sufficiently higher unsaturation compared to products obtained in other way. In our previous researches a number of silica-alumina materials, including natural and synthetic zeolites, as well as various clay materials, were studied as oligomerization catalysts. These materials were used in their natural state and after acid activation. The research showed that the activation considerably improved the effectiveness of the investigated heterogeneous catalysts, especially swelling clays. The activated palygorskite and the activated bentonite clay were found to be the most effective from all investigated catalysts. The aluminosilicates named above are very cheap materials. There are big deposits of clay materials in Ukraine. Bentonite deposits are developed in Cherkasy region (Dashukivka bentonite deposit -104.7 million ton) and Transcarpathian region. There are also known deposits in Donbas, Khmelnitski region and Crimea. Palygorskite is procured from Cherkasy deposit. There are also palygorskite deposits found near Korosten and Simferopol [3]. Considering above-said, it was decided to investigate a cooligomerization process in the presence of these catalysts in detail. Another important task is investigation of the catalysts themselves. It should allow to ascertain the relation between the results achieved using the catalyst and the properties of this catalyst.

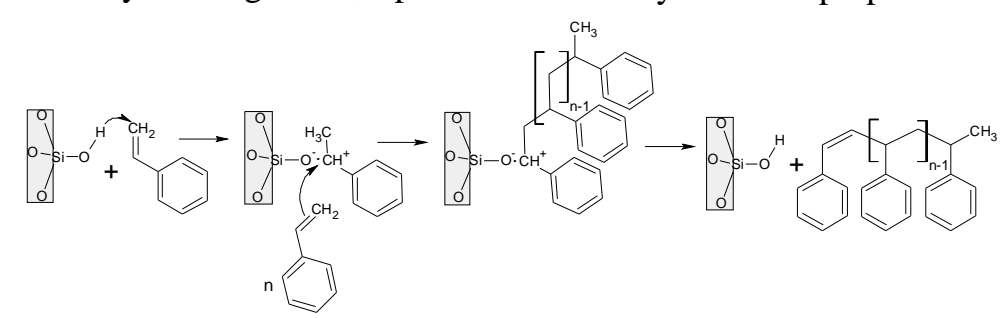

Fig. 1. The scheme of heterogeneous catalytic oligomerization on the surface active site 


\section{Experimental}

\subsection{Research $O$ bject}

The object of our research was the $\mathrm{C}_{9}$ fraction of diesel fuel pyrolysis liquid products (DFPLP). The content of polymerizable (unsaturated) components in this fraction is about $55 \%$ by wt. Styrene $(\approx 19 \%)$, dicyclopentadiene $(\approx 18 \%)$ and vinyltoluenes $(\approx 8 \%)$ are the main ones of them. The main saturated component of $\mathrm{C}_{9}$ fraction is xylene.

\subsection{Catalyst Preparation}

The catalysts preparation was carried out by activation of natural silica-alumina materials: palygorskite and bentonite clay with acid solution. Activation was carried out with $13 \%$ by wt. solution of sulfuric acid in such amount that the weight of acid monohydrate was $60 \%$ of dry aluminosilicate weight. The activation temperature was $373 \mathrm{~K}$, process duration $-6 \mathrm{~h}$ [4-6]. The clay and acid have been continuously stirred. After activation the clay was washed with distilled water several times. The washed catalyst was filtered out and dried.

\subsection{Oligomerization}

The $\mathrm{C}_{9}$ fraction of DFPLP cooligomerization process was carried out in a three neck flask fitted with a stirrer and condenser in argon atmosphere. The flask was placed into a thermostat heated to the process temperature. The process was carried out at temperatures of 333-413K during $1-6 \mathrm{~h}$ at constant intensive stirring. The catalyst content in the reaction mixture was $1-15 \%$ by wt. Before using the catalyst was dried at 373-423K for $1 \mathrm{~h}$. After cooligomerization the catalyst was filtered out under vacuum. Atmospheric and vacuum strippings were carried out to obtain the final product in residue.

\subsection{Determination of Cooligomer Properties}

The cooligomer colour was determined comparing $10 \%$ cooligomer solution in benzene with standard iodine scale. The bromine number (unsaturation) was determined by iodometric back titration according to common technique. The softening point was defined by ring and ball method. The cooligomer average molar weight was defined by cryoscopic method in a benzene solution. The cooligomer density was defined using a Westphal-Mohr balance. The density of the cooligomerizate before stripping was also defined with an areometer.

\subsection{Catalysts Investigation}

\subsubsection{Determination of catalysts specific surface area}

Determination of the specific surface area was carried out by methylene blue adsorption method according to the following technique. Methylene blue solution was prepared by mixing $1 \mathrm{~g}$ of methylene blue dry powder with $200 \mathrm{ml}$ of deionized water. Three grams of oven-dried catalyst were mixed with $10 \mathrm{ml}$ of deionized water. The suspension was intensively stirred by a magnetic stirrer during titration. The methylene blue solution was added into this suspension with $0.5 \mathrm{ml}$ increments. After each addition the suspension was mixed for $1 \mathrm{~min}$. Then a small drop was removed from the suspension with a glass stick and placed onto a filter paper. If the unadsorbed methylene blue is present in the solution it forms a permanent blue halo around the suspension aggregate spot [7]. It means that methylene blue has covered all the surface of the investigated sample (end-point). The catalyst specific surface area $\left(S S A, \mathrm{~m}^{2} / \mathrm{g}\right)$ may be determined from the value of methylene blue solution volume $\left(V_{M B}^{\text {titr. }}, \mathrm{ml}\right)$ added until complete surface covering:

$$
S S A=\frac{V_{M B}^{t i t r} \cdot N_{A} \cdot S_{M B} \cdot m_{M B}}{M_{M B} \cdot V_{M B} \cdot m_{c a t}}
$$

where $M_{M B}$ - the methylene blue molar weight $\left(M_{M B}=319.87 \mathrm{~g} / \mathrm{mol}\right) ; N_{A}$ - the Avogadro's number $\left(N_{A}=6.023 \cdot 10^{23} \mathrm{~mol}^{-1}\right) ; S_{M B}-$ the area covered with one methylene blue molecule $\left(S_{M B}=130 \AA^{2}\right) ; m_{M B}$ - the mass of methylene blue used for solution preparation; $V_{M B}-$ the volume of the prepared methylene blue solution; $V_{M B}^{\text {titr. }}$ the methylene blue solution volume used for titration; $m_{\text {cat }}-$ the mass of the catalyst batch.

\subsubsection{Determination of active sites concentration}

The active sites concentration was determined by a potentiometric titration method. The catalysts samples were dried in a drying oven at $373-423 \mathrm{~K}$ to constant weight. The potentiometric titration experiment was done in a 100-ml Erlenmeyer flask. Thereto the catalyst suspension in distilled water was prepared. Such amount of the catalyst was weighed to give the suspension concentration of $5 \mathrm{~g} / \mathrm{l}$ in $80 \mathrm{ml}$ of distilled water. The background electrolyte $\mathrm{NaNO}_{3}$ was added to the solution in such amount to give ionic strength of $0.005 \mathrm{~mol} / \mathrm{l}$. Afterwards, $0.1 \mathrm{~N} \mathrm{HNO}_{3}$ solution was gradually added to the suspension in $0.1 \mathrm{ml}$ increments until $\mathrm{pH}$ value becomes approximately equal to 3 . The suspension was intensively stirred with a magnetic stirrer during acidification. Before the beginning of the 
titration the sample was intensively stirred for another hour to make the electrode potential completely equilibrated. The titration was carried out with $0.2 \mathrm{~N} \mathrm{NaOH}$ solution uner intensive stirring. The titrant solution was added gradually in $0.1 \mathrm{ml}$ increments. After each addition when the electrode potential was equilibrated, $\mathrm{pH}$ value was recorded. During the titration process, the suspension was continually bubbled with argon to exclude the effect of $\mathrm{CO}_{2}$. The titration was carried out until the suspension $\mathrm{pH}$ became greater than 10. The blank titration was carried out in the same manner. But in this case after suspension preparation and its acidification with nitric acid solution the catalyst was filtered out and the obtained filtrate was titrated $[8,9]$.

For the total active acid sites concentration determination in situ the Gran plot method was used. For the hydroxide back titration, Gran functions are as follows:

Acid side $(\mathrm{pH} \leq 7)$ :

$$
\begin{gathered}
G=\left(V_{0}+V_{\mathrm{HNO}_{3}}+V_{\mathrm{NaOH}}\right) \cdot 10^{\frac{E}{59.175}}= \\
=\left(V_{0}+V_{\mathrm{HNO}_{3}}+V_{\mathrm{NaOH}}\right) \cdot 10^{-\mathrm{pH}} \cdot 100
\end{gathered}
$$

Alkaline side $(\mathrm{pH} \geq 7)$ :

$$
\begin{aligned}
G & =\left(V_{0}+V_{\mathrm{HNO}_{3}}+V_{\mathrm{NaOH}}\right) \cdot 10^{-\frac{E}{59.175}}= \\
& =\left(V_{0}+V_{\mathrm{HNO}_{3}}+V_{\mathrm{NaOH}}\right) \cdot 10^{-(13,8-\mathrm{pH})} \cdot 100
\end{aligned}
$$

where $G$ - Gran function; $V_{0}$ - the initial volume of suspension, ml; $V_{\mathrm{HNO} 3}$ - the total volume of $\mathrm{HNO}_{3}$ solution added to the suspension, $\mathrm{ml} ; V_{\mathrm{NaOH}}$ - the volume of added titrant solution $(\mathrm{NaOH}), \mathrm{ml} ; E$ - the potential of the glass electrode being a function of $\mathrm{pH}$ of suspension at each titration point, $\mathrm{mV}$.

During titration the added hydroxide ions successively participate in the following processes. Initially they take part in neutralization of the excess $\mathrm{H}^{+}$(before the equivalence point $V_{\mathrm{NaOH} 1}^{e}$ ). Then hydroxide ions are bound due to the interaction with the surface active sites (between the equivalence points $V_{\mathrm{NaOH} 1}^{e}$ and $V_{\mathrm{NaOH} 2}^{e}$ ):

$$
\equiv \mathrm{Si}-\mathrm{O}-\mathrm{H}+{ }^{-} \mathrm{OH}=\equiv \mathrm{Si}-\mathrm{O}^{-}+\mathrm{H}_{2} \mathrm{O}
$$

After that $\mathrm{pH}$ value increases, because of the excess $\mathrm{OH}^{-}$ions addition (after the equivalence point $V_{\mathrm{NaOH} 2}^{e}$ ). Consequently, $V_{\mathrm{NaOH} 1}^{e}$ in Gran plots was regarded as the zero point of surface titration, since only acid-base neutralization occurred in solution before this point. The difference between the volumes $V_{\mathrm{NaOH} 1}^{e}$ and $V_{\mathrm{NaOH} 2}^{e}$, representing the amount of the base bound with the surface active sites, is the main quantity to determine. Generally, in situ the Gran plot approach is the linear regression analysis of Gran function $(G)$ versus the volume of added base solution $\left(V_{\mathrm{NaOH}}\right)$, that allows to determine two equivalence points for each catalyst sample $\left(V_{\mathrm{NaOH} 1}^{e}\right.$ and $\left.V_{\mathrm{NaOH} 2}^{e}\right)$ and for each blank system $\left(V^{e}{ }_{\mathrm{NaOH} 1}\right.$ та $\left.V^{e}{ }_{\mathrm{NaOH}}\right)$. The equivalence points are found as the intercepts of tangents to acidic and alkaline Gran plot sides at the abscissa axis [8]. Having defined from the Gran plots all the volumes of titrant, corresponding to equivalence points, for all the catalysts samples and blanks, we can calculate the total active sites concentration for each one of the investigated catalysts $(\mathrm{mmol} / \mathrm{g})(5)$ :

$$
H_{S}=\frac{\left[\left(V_{\mathrm{NaOH} 1}^{e}-V_{\mathrm{NaOH} 2}^{e}\right)-\left(V_{\mathrm{NaOH} 2}^{e}-V_{\mathrm{NaOH} 1}^{e}\right)\right] \cdot C_{\mathrm{NaOH}}}{m_{\text {cat }}}
$$

where $\mathrm{C}_{\mathrm{NaOH}}-$ the base solution normality $\left(C_{\mathrm{NaOH}}=0.19993 \mathrm{~mol} / \mathrm{l}\right) ; m_{\text {cat. }}-$ the weight of the catalyst, used for suspension preparation, $\mathrm{g}$.

\subsubsection{Determination of active sites strength and ratio}

To determine the main parameters characterizing a catalyst, we used a computer program ProtoFit (Version 2.0), which is designed to determine the surface active sites concentration and strength (dissociation equilibrium constants) on the basis of the potentiometric titration data. This program allows to determine the named parameters by optimizing thereof on the basis of the chosen theoretical model by a least-squares method. For optimization you should choose the following parameters: the model of titrant interaction with the surface (the Double Layer Model, the Constant Capacitance Model, the Donnan Sell Model and non-electrostatic adsorption model), the method of activity coefficients calculation (Extended Debye-Huckel equation, the Davies equation, the Truesdell-Jones equation or $\gamma=1$ ), and the number of active sites types. The program allows to choose from one to four active sites types.

The initial data to be set includes first of all potentiometric titration results $(\mathrm{pH}$ values and volumes of titrant added, corresponding to these values of $\mathrm{pH}$ ), the initial volume of suspension, the mass of the catalyst, titrant solution normality, the catalyst specific surface area, the absolute temperature and the background electrolyte $\left(\mathrm{NaNO}_{3}\right)$ concentration.

The program data-out includes the reaction (4) equilibrium constant logarithm, characterizing the acid site strength, as well as the logarithm of these sites concentration $(\lg \mathrm{H})$. If the chosen number of the active sites types is more than one (from 2 to 4 ) the program calculates $\operatorname{lgK}$ and $\lg \mathrm{H}$ for each type. In addition to values of $\operatorname{lgK}$ and $\operatorname{lgH}$ the program calculates the values of squares sum of differences between the values of derivatives of the model proton-exchange function and protonexchange function calculated from the titration data 
(later simply the sum of squares). The sum of squares value allows to judge about the adequacy and accuracy of the results [12]. The lower sum of squares values denotes more adequate results. Thus by the sum of squares value we can identify which of four models of titrant interaction with the surface is most adequate, which of the formulas for activity coefficient calculation is most agreed with the titration results, how many types of active sites are present on the catalyst surface. So, those results are selected for which the sum of squares value is minimal.

Besides the sum of squares values, the total active sites concentration values were the criterion of optimal model choosing. The closer the value of this parameter to the one calculated by the Gran plot method, the more accurate and adequate the selected model is.

\subsubsection{Electron microscopy}

The activated palygorsite and the activated bentonite clay were investigated using scanning electron microscope REM-106I. The electron mocroscopic investigations should help to determine whether there is an appreciable difference in structure of two above mentioned catalysts.

\section{Results and Discussion}

\subsection{Cooligomer Yield}

The dependence of the cooligomer yield on catalyst concentration, time and temperature (Figs. 2-4) are similar for the activated palygorskite and the activated bentonite clay. Increasing the catalyst content the cooligomer yield increases linearly. Temperature increasing also causes the yield increase close to linear, however with some acceleration at high temperatures. Concerning the duration influence, the bulk of the product is generated already during the first hour and then the yield increases slower and slower.

In all cases the activated palygorskite allows to obtain the lower cooligomer yield compared with the activated bentonite clay. It is worth noting, that this difference becomes more apparent, the more severe process conditions are (higher catalyst concentration, longer time, higher temperature). Thus, if in case of $10 \%$ or $15 \%$ catalyst content the difference in yield is appreciable (1.5 and $2.25 \%$ by wt., respectively), than in case of lower concentrations this difference decreases and practically disappears at the catalyst concentration of $1 \%$ by wt. Likewise, when cooligomerization duration increases: in case of $6 \mathrm{~h}$ the difference in yields is $3 \%$, in case of $3 \mathrm{~h}-$ $2.25 \%$, and in case of $1 \mathrm{~h}-$ only $1.18 \%$. The difference in yields for palygorskite and bentonite clay becomes most apparent at high cooligomerization temperatures. Here it reaches $6.39 \%$ by wt. at $413 \mathrm{~K}$, remains equal $5.51 \%$ by wt. at $373-393 \mathrm{~K}$, and at 353 and $333 \mathrm{~K}$ dramatically decreases to $2.25 \%$ and $1.3 \%$ by wt., respectively.

The oligomerizate density varies when changing the process conditions similarly to the cooligomer yield variation. There is a quantitative dependence between the oligomerizate density and the cooligomer yield, described by the empirical linear equation: $\eta=0.7544 \cdot \rho_{\text {olig. }}-693.37$. Herein the approximation accuracy is $R^{2}=0.9904$, that allows to speak about the possibility of rather accurate prediction of yield values from the values of the oligomerizate density.

\subsection{Cooligomer Properties}

The properties of the cooligomers, obtained in the presence of the activated palygorskite, in general, are close to properties of the product obtained in the presence of the activated bentonite clay. When changing the process conditions there are the same tendencies in changing the cooligomer properties in the presence of activated palygorskite as in the presence of activated bentonite clay. This indicates the similarity of the process behavior in the presence of different corpuscular aluminosilicates. However, the number of important distinctions in the product properties may be noticed.

\subsubsection{Average molar weight}

The average molar weight of the cooligomers obtained in our process varies depending on the cooligomerization condition in the range from 549.7 to $933.6 \mathrm{~g} / \mathrm{mol}$ when using the activated bentonite clay and from 661.2 to $950.7 \mathrm{~g} / \mathrm{mol}$ when using the activated palygorskite as a catalyst. The activated palygorskite allows to obtain the product with higher average molar weight under all studied cooligomerization conditions (except $413 \mathrm{~K}, 3 \mathrm{~h}$ and $15 \%$ by wt. of the catalyst, when the molar weight values are practically equal). And this difference increases when the temperature increases (except at the temperature of $413 \mathrm{~K}$ ) (Fig. 7), when the duration and the catalyst concentration increase. The cooligomers with very close molar weight are obtained at the duration of $1 \mathrm{~h} \mathrm{(353} \mathrm{K,} 15 \%$ by wt.) (Fig. 6) and the catalyst concentration of $1 \%$ by wt. (353 K, $3 \mathrm{~h}$ ) (Fig. 5). In addition we can state that using the activated palygorskite the cooligomer molar weight remains rather stable when the process conditions are changed, while using the activated bentonite clay the molar weight varies in a sufficiently wide range.

\subsubsection{Softening point}

The character of the cooligomer softening point dependence on cooligomerization conditions (Figs. 8-10) is very close to the character of the respective dependences of average molar weight. Evidently, the cooligomer softening point is the function of the cooligomer molar weight. 


\subsubsection{Bromine number}

High unsaturation of cooligomers is one of the important advantages of the heterogeneous catalytic process proposed by us. Both the activated palygorskite and the activated bentonite clay allow to obtain products with high bromine number values.
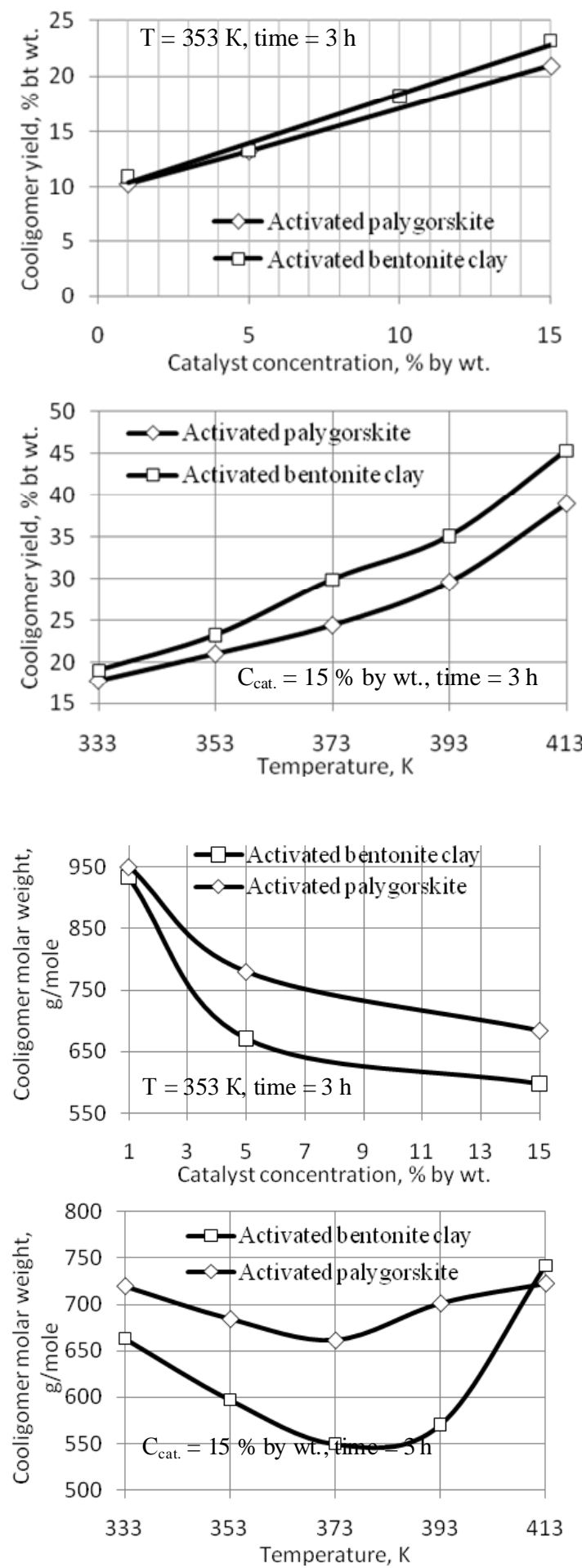

Generally, the bromine number values are close for the catalysts. The average value for all the cooligomer samples is $70.00 \mathrm{~g} \mathrm{Br}_{2} / 100 \mathrm{~g}$ for the activated palygorskite and $70.53 \mathrm{~g} \mathrm{Br}_{2} / 100 \mathrm{~g}$ for the activated bentonite clay. Any clear dependences of the bromine number on temperature or time are not observed. The bromine number values

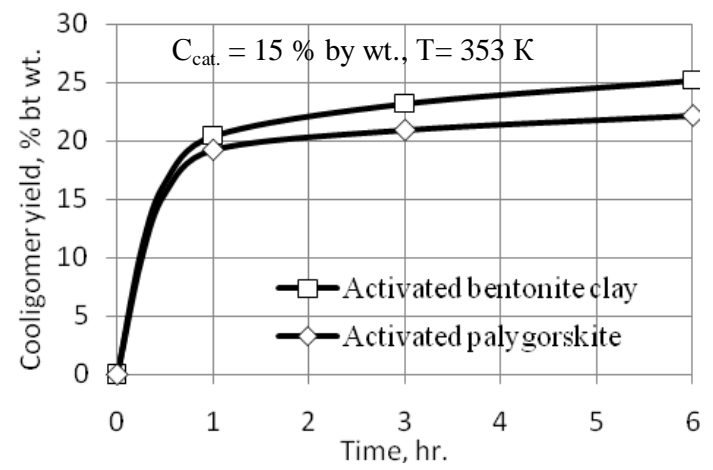

Figs. 2-4. The dependence of cooligomer yield on cooligomerization conditions (catalyst concentration, time and temperature)

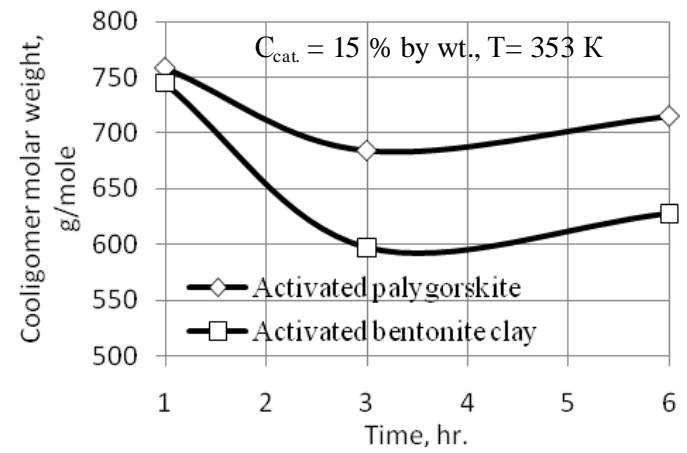

Figs. 5-7. The dependence of the coolig omer average molar weig] on cooligomerization conditions (catalyst concentration, time an temperature) 

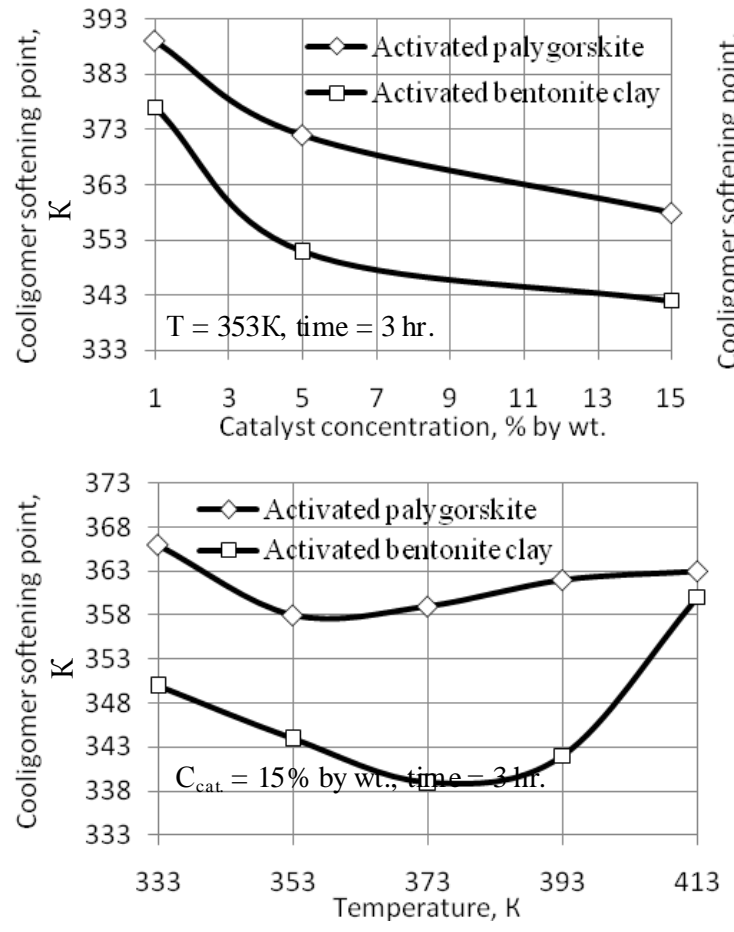

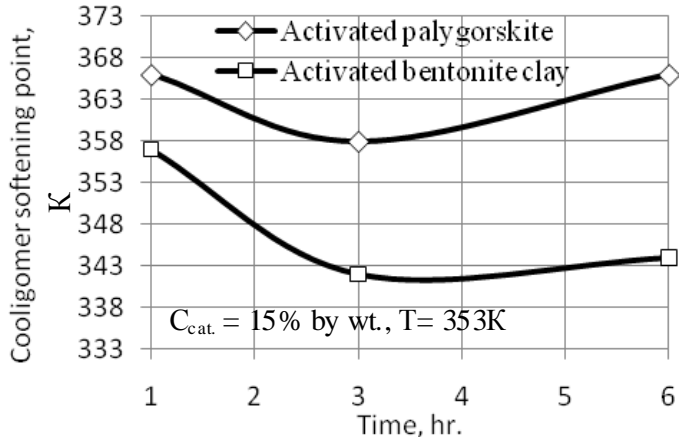

Figs. 8-10. The depend ences of the cooligomer softening point cooligomerization conditions (catalyst concentration, time and temperature)

Table 1

The dependence of the cooligomer bromine number on cooligomerization conditions

\begin{tabular}{|c|c|c|c|c|c|c|c|c|c|c|c|}
\hline Time, $\mathrm{h}$ & \multicolumn{3}{|c|}{3} & \multicolumn{3}{c|}{3} & 1 & 3 & 6 \\
\hline Temperature, $\mathrm{K}$ & \multicolumn{3}{|c|}{353} & 333 & 353 & 373 & 393 & 413 & \multicolumn{3}{c|}{353} \\
\hline $\begin{array}{c}\text { Catalyst concentration, } \\
\text { \% by wt. }\end{array}$ & 1 & 5 & 15 & \multicolumn{5}{|c|}{15} & \multicolumn{3}{c|}{15} \\
\hline Activated palygorskite & 67.03 & 69.87 & 72.54 & 66.03 & 72.54 & 71.80 & 69.76 & 73.81 & 68.01 & 72.54 & 66.10 \\
\hline $\begin{array}{c}\text { Activated } \\
\text { bentonite clay }\end{array}$ & 66.01 & 66.45 & 69.90 & 70.99 & 69.90 & 68.53 & 78.01 & 75.14 & 71.38 & 69.90 & 69.65 \\
\hline
\end{tabular}
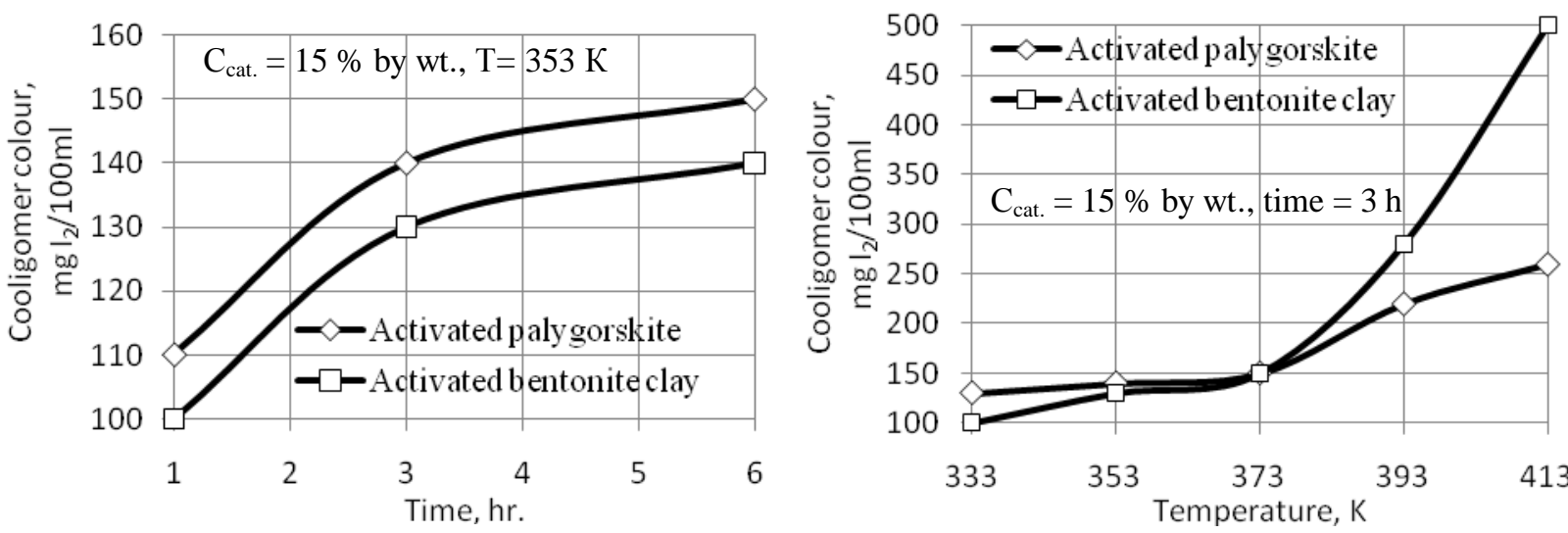

Figs. 11-12. The dependence of the cooligomer colour on cooligomerization time and temperature 
rather randomly vary in the range from 66.01 to $78.01 \mathrm{~g}$ $\mathrm{Br}_{2} / 100 \mathrm{~g}$ for bentonite clay and from 66.10 to $73.81 \mathrm{~g}$ $\mathrm{Br}_{2} / 100 \mathrm{~g}$ for palygorskite. Increasing the catalyst concentration the cooligomer bromine number increases. And it is higher for the activated palygorskite under these conditions $(353 \mathrm{~K}, 3 \mathrm{~h})$. In general at lower temperatures $(333-373 \mathrm{~K})$ and time of $3 \mathrm{~h}$ the product with higher unsaturation is obtained in the presence of the activated palygorskite. At $393-413 \mathrm{~K}$ the cooligomer obtained in the presence of the activated bentonite clay has higher bromine number.

\subsubsection{Colour}

The obtained cooligomers are transparent materials, having the colour from peach to dark red. The product colour does not depend on the catalyst concentration, and when changing its content from 1 to $15 \%$ by wt. at constant temperature and duration the colour remains constant. The colour of the cooligomer obtained at the temperature of $353 \mathrm{~K}$ and time of $3 \mathrm{~h}$ is $130 \mathrm{mg} \mathrm{I}_{2} / 100 \mathrm{ml}$ in case using of the activated bentonite clay as a catalyst, and $140 \mathrm{mg} \mathrm{I}_{2} / 100 \mathrm{ml}$ in case of using the activated palygorskite.

The colour is a little worse for palygorskite at low temperatures ( 333 and $353 \mathrm{~K}$ ). So, at $353 \mathrm{~K}$ the colour of the product obtained in the presence of the activated palygorskite is 10 units darker than the colour of the product obtained in the presence of the activated bentonite clay. And this difference remains constant when changing the cooligomerization time (Fig. 11). The important feature of the activated palygorskite is the fact that the product colour does not increase so dramatically at high temperatures as it occurs when using the activated bentonite clay. Thus the cooligomer obtained in the presence of the activated palygorskite at $413 \mathrm{~K}$ has the colour of $260 \mathrm{mgI}_{2} / 100 \mathrm{ml}$, while the product obtained under the same conditions in the presence of the activated bentonite clay has the colour of 500 units (Fig. 12). This is an important advantage of palygorskite, especially when the cooligomers with light colour are required.

\subsubsection{Density}

The cooligomers obtained by heterogeneous catalytic method for the $\mathrm{C}_{9}$ fraction of DFPLP are hard glassy materials. They belong to low density materials.

Any clear cooligomerization conditions dependence of the cooligomer density is not observed. The values of the product density vary in sufficiently narrow range. The product density increased appreciably only at $413 \mathrm{~K}$ in the presence of the activated bentonite clay. Generally, despite the variations of the cooligomer density values, it could be said, that the density increases when the process temperature increases. It should be noted that the lowest density values belong to the cooligomers samples having the highest molar weight. This may be explained as follows: the smaller the cooligomer macromolecules are, the more closely they may be packed, and thus the product density is higher. The cooligomers density values are very close for the investigated catalysts. The average value of density calculated for all the samples obtained when using the activated palygorskite is $1072.6 \mathrm{~kg} / \mathrm{m}^{3}$ and for the samples obtained when using the activated bentonite clay is $1073.2 \mathrm{~kg} / \mathrm{m}^{3}$, so the difference is only $0.6 \mathrm{~kg} / \mathrm{m}^{3}$.

\subsection{Catalysts Properties}

When using the activated palygorskite and the activated bentonite clay the results with a number of distinctions were obtained. To explain, why the yields and properties of the product obtained under same conditions when using different catalysts differ, it is necessary to determine the catalysts properties. Thereto the respective investigations were carried out. Particularly, electron microscopy investigations were carried out, and such key parameters for heterogeneous catalysis, as specific surface area, the active sites concentration and strength were determined.

\subsubsection{M icroscopy}

The obtained images confirm that the catalysts have a very similar structure. Polydyspersity is characteristic for these materials. The separate particles dimentions vary in a very wide range: from few dozens of nanometers (Figs. 15-16) to more than $50 \mu \mathrm{m}$ in case of large agregates (Figs. 13-14). The average particle dementions are approximately the same. The difference between the catalysts consists in the fact, that the activated palygorskite has fewer smal particles and more large agregates compared to the activated bentonite clay (Figs. 13-14).

At high magnification $(\times 8000)$ it is visible that the particles have a layered (lamellar) structure, i.e. cinsist of layers (sheets), being more or less adjacet to each other (Figs. 15-16). This feature concerns both palygorskite and bentonite clay.

\subsubsection{Specific surface area}

The values of the investigated catalysts specific surface area are given in Table 3. As we can see these values are very close. The difference is only $4.03 \mathrm{~m}^{2} / \mathrm{g}$ (that is about $6 \%$ ). The activated palygorskite has greater specific surface area. The activated bentonite clay allows to achieve higher yield. So, the specific surface area is not the cause of difference in the catalysts activity. 


\subsubsection{Active sites concentration}

The potentiometric titration of the catalysts samples and blanks gave the following results (Figs. 17-18).

As we can see the catalysts suspensions potentiometric titration curves are more flat at the titration jump and the jump is flatter compared with the curves for the blanks. This suggests that some amount of the titrant is spent on the interaction with acidic sites of the catalyst surface.

The results of definitions and calculations are given in Table 3 . The active sites concentration is given in various units.

Table 2

The dependence of the cooligomer density on cooligomerization conditions

\begin{tabular}{|c|c|c|c|c|c|c|c|c|c|c|c|}
\hline Time, $\mathrm{h}$ & \multicolumn{3}{|c|}{3} & \multicolumn{3}{c|}{3} & 1 & 3 & 6 \\
\hline Temperature, $\mathrm{K}$ & \multicolumn{3}{|c|}{353} & 333 & 353 & 373 & 393 & 413 & \multicolumn{3}{c|}{353} \\
\hline $\begin{array}{c}\text { Catalyst concentration, } \\
\% \text { by wt. }\end{array}$ & 1 & 5 & 15 & \multicolumn{9}{|c|}{15} \\
\hline $\begin{array}{c}\text { Activated } \\
\text { palygorskite }\end{array}$ & 1067.5 & 1071.0 & 1073.2 & 1068.5 & 1073.2 & 1073.2 & 1077.7 & 1078.3 & 1070.1 & 1073.2 & 1072.6 \\
\hline $\begin{array}{c}\text { Activated } \\
\text { bentonite clay }\end{array}$ & 1069.0 & 1072.2 & 1070.1 & 1072.7 & 1070.1 & 1073.9 & 1074.0 & 1086.8 & 1074.8 & 1070.1 & 1071.3 \\
\hline
\end{tabular}
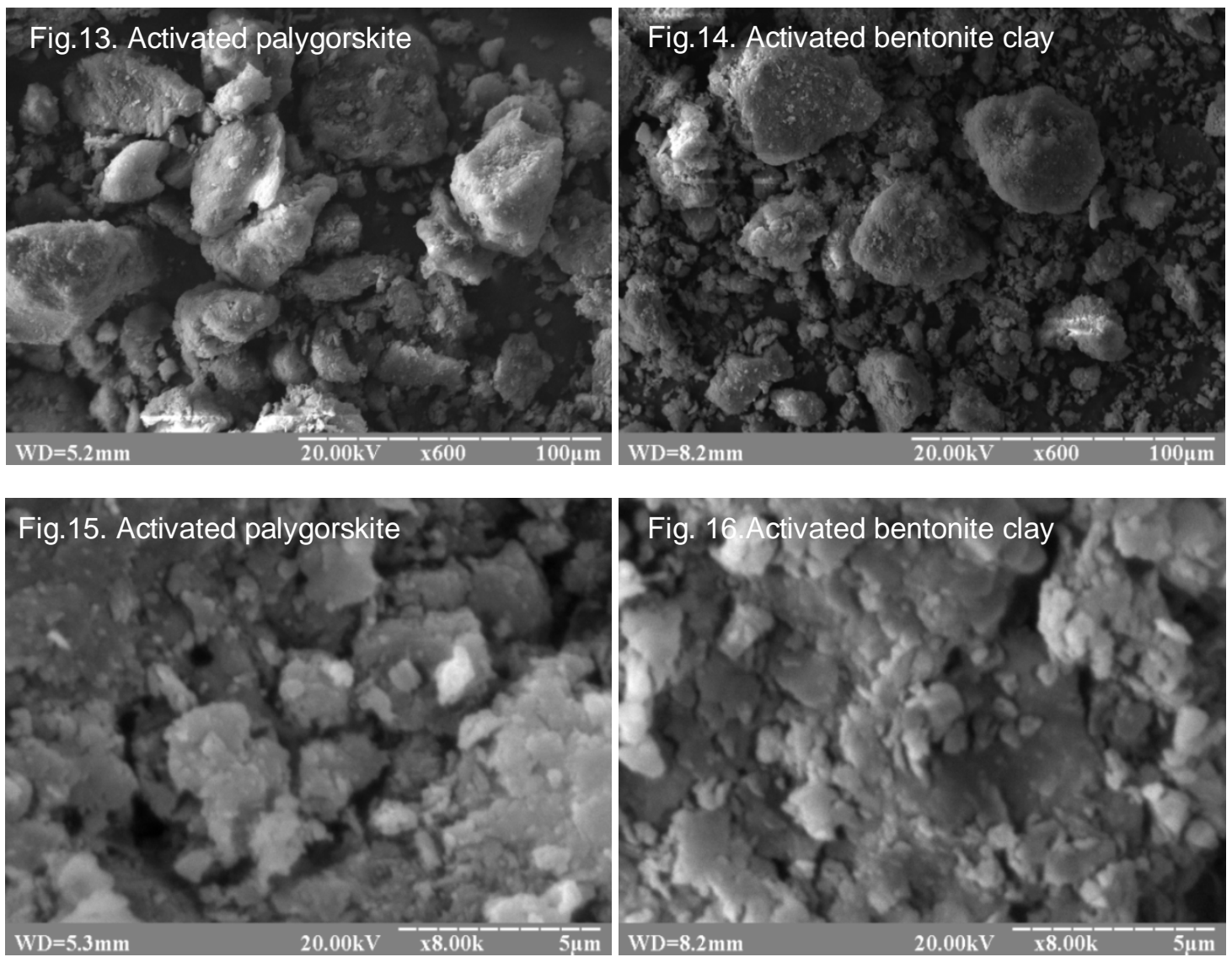

Figs. 13-16. Electron microscopy images of the activated palygorskite (on the left) and the activated bentonite clay (on the right) with magnification $600 \times$ and $8000 \times$ 


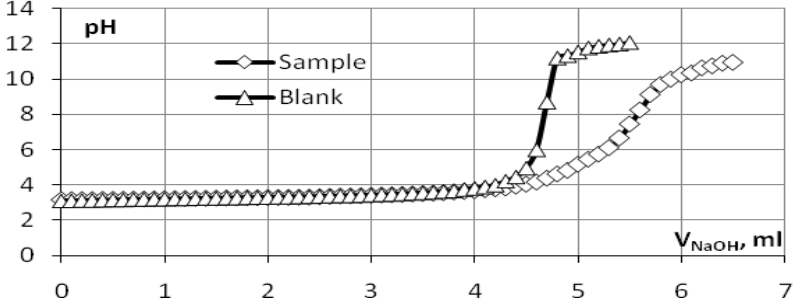

Fig. 17. The activated bentonite clay potentiometric titration curves (sample and blank)

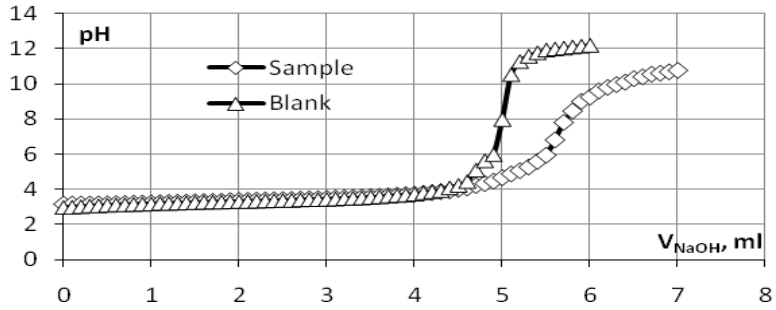

Fig. 18. The activated palygorskite potentiometric titration curves (sample and blank)

Table 3

The results of determination the catalysts specific surface area and active sites concentration

\begin{tabular}{|c|c|c|c|c|c|c|c|c|c|}
\hline \multirow{2}{*}{ Catalyst } & \multirow{2}{*}{$\begin{array}{l}\mathrm{SSA}, \\
\mathrm{m}^{2} / \mathrm{g}\end{array}$} & \multirow{2}{*}{$\begin{array}{c}m_{\text {cat }}, \\
\mathrm{g}\end{array}$} & \multirow{2}{*}{$\begin{array}{c}V_{\mathrm{NaOH} 1}^{e}, \\
\mathrm{ml}\end{array}$} & \multirow{2}{*}{$\begin{array}{c}V_{\mathrm{NaOH} 2}^{e}, \\
\mathrm{ml}\end{array}$} & \multirow{2}{*}{$\begin{array}{c}V_{\mathrm{NaOH},}, \\
\mathrm{ml}\end{array}$} & \multirow{2}{*}{$\begin{array}{c}V^{\prime \prime}{ }_{\mathrm{NaOH} 2}, \\
\mathrm{ml}\end{array}$} & \multicolumn{3}{|c|}{$H_{S}$} \\
\hline & & & & & & & $\mathrm{mmol} / \mathrm{g}$ & sites/g & sites $/ \mathrm{nm}^{2}$ \\
\hline $\begin{array}{l}\text { Activated } \\
\text { palygorskite }\end{array}$ & 69.17 & 0.3998 & 5.0 & 6.3 & 4.7 & 5.1 & 0.40006 & $2.40956 \cdot 10^{20}$ & 3.4835 \\
\hline $\begin{array}{l}\text { Activated } \\
\text { bentonite clay }\end{array}$ & 65.14 & 0.3993 & 4.8 & 5.9 & 4.6 & 4.7 & 0.50070 & $3.01572 \cdot 10^{20}$ & 4.6296 \\
\hline
\end{tabular}

The values of strength and concentration of active sites of each type

Table 4

\begin{tabular}{|c|c|c|c|c|c|c|c|c|}
\hline Catalyst & $p K_{1}$ & $\begin{array}{c}H_{1}, \\
\mathrm{mmol} / \mathrm{g}\end{array}$ & $p K_{2}$ & $H_{2}, \mathrm{mmol} / \mathrm{g}$ & $p K_{3}$ & $H_{3}, \mathrm{mmol} / \mathrm{g}$ & $p K_{4}$ & $H_{4}, \mathrm{mmol} / \mathrm{g}$ \\
\hline Activated palygorskite & 10.165 & 0.45709 & 4.813 & 0.42756 & 8.498 & 0.13804 & 6.367 & 0.09226 \\
\hline Activated bentonite clay & 4.630 & 0.26182 & 10.095 & 0.21928 & 5.874 & 0.19679 & 7.859 & 0.11272 \\
\hline
\end{tabular}

The obtained results indicate rather high active sites concentration of the investigated activated aluminosilicates. As it is clear from Table 3 the activated bentonite clay has higher active sites concentration than the activated palygorskite. Obviously, this factor causes the activated bentonite clay to be more effective catalyst, than the activated palygorskite.

Concerning the relation between cooligomer properties and active sites concentration, we can state, that the catalyst with less active sites concentration (activated palygorskite) allows to obtain the product with higher average molar weight and softening point, and vice versa. This regularity may be explained as follows. The greater is the catalyst active sites concentration the greater is their number present in the reaction mixture, when the weight content of the catalyst is constant. Consequently, in the presence of the catalyst with greater active sites concentration more oligomer chains are initiated simultaneously. This results in lower average molar weight of the obtained products, especially in consideration of the limited content of unsaturated components and relatively short time of the process. However, the difference in the active sites concentration is relatively small, while the difference in the product molar weight values reaches $130.28 \mathrm{~g} / \mathrm{mol}$ (> 20\%). So, probably there are other factors, causing the activated palygorskite to allow obtaining cooligomers having higher molar weight.

\subsubsection{Active sites strength}

For both the activated bentonite clay and the activated palygorskite the minimum sum of squares values corresponds to the model with four types of active sites. Thus, we can state, that there are at least four types of active sites on the catalysts surface. The non-electrostatic adsorption model was found to be the most adequate among the models of titrant interaction with the surface. This fact indicates that the active sites of the investigated catalysts generally are in non dissociated state. And the catalysts surface is thus electrically neutral. The values of the active sites strength and concentrations corresponding to active sites of each type are the most accurate for this model. Concerning the activity coefficient calculation method, the most accurate values are obtained assuming $\gamma$ $=1$. The values of strength $\left(p K_{i}\right)$ and concentration of the active sites of each type $\left(H_{i}\right)$ are given in Table 4.

The properties of the active sites of various catalysts are the cause of above facts. In the activated 
palygorskite about $41 \%$ of the active sites are weak $(p K=10.165)$, while in the activated bentonite clay there is about $28 \%$ of weak sites (Table 4). Probably, this feature substantially causes the product with higher molar weight to be obtained in the presence of activated palygorskite. The cause of the fact, that cooligomers having higher molar weight are obtained in the presence of the catalysts having higher content of the weak active sites, is the following. The cooligomer chain growing on the active acid surface site comes off (Fig. 1) easier the stronger the active site is. The growing oligomer chain, being macrocarbocation per se, is bound with negatively charged counterion by electrostatic force. In case of stronger active site the electron density is pulled from the oxygen atom more strongly and the negative charge on it is reduced. As a result the electrostatic force, holding the growing macrocarbocation, weakens. Thus, the same factor allowing the surface hydroxyl groups to dissiciate easily, promotes the easier cooligomer chain detachment. The easier (and thus more rapidly) the growing cooligomer chains comes off, the lower the value of the final cooligomeric product average molar weight is.

\section{Conclusions}

The investigations carried out by us allowed to ascertain the features of $\mathrm{C}_{9}$ fraction of DFPLP cooligomerization in the presence of the activated palygorskite and the activated bentonite clay as catalysts. It has been ascertain how the product yields and properties vary depending on the cooligomerization process conditions. This allowed to compare the catalysts and chose the optimal conditions for the process in the presence thereof. The optimal conditions may be said to be the catalyst concentration of $15 \%$ by wt., duration of 1-3 h. The optimal temperature depends on the cooligomers application field. If the product light colour is required, the optimal temperature may be said to be 353$373 \mathrm{~K}$ for the activated bentonite clay and 353-393 K for the activated palygorskite. If light colour is not a necessary requirement the optimal temperature may be said to be $393-413 \mathrm{~K}$. Both catalysts allow to obtain the cooligomers with relatively close yields and sufficiently closed properties.

The activated palygorskite is less effective catalyst (allows to achieve higher yields) than the activated bentonite clay. The cooligomers obtained when using the activated palygorskite exceed the cooligomers obtained in the presence of the activated bentonite clay almost in all parameters. First of all it means higher average molar weight and softening point, as well as lighter colour of the product obtained at high temperatures. In general, all the properties of the cooligomers obtained when using the activated palygorskite remains more stable when process conditions are changed, compared to cooligomers obtained in the presence of the activated bentonite clay.

The catalysts properties investigation allowed to find that higher active acid surface sites concentration is the cause of higher effectiveness of the activated bentonite clay. The same cause partly stipulates the lower molar weight of the product obtained when using this catalyst. Another cause of higher molar weight of the product, obtained in the presence of the activated palygorskite, is a significant content of the weak active sites on this catalyst surface.

Although the activated bentonite clay is a more effective catalyst (allows to achieve higher yields) than the activated palygorskite, the difference is not considerable, and the properties of the cooligomers obtained when using the activated palygorskite are a little better. So, both the activated palygorskite and the activated bentonite clay may be said to be effective oligomerization catalysts.

\section{References}

[1] Varma R.: Tetrahedron, 2002, 58, 1235.

[2] Knuniants I.: Khimicheskaya Encyklopediya. Sovetskaya Entsyklopediya, Moskwa 1988.

[3] Biletskyi V.: Mala Girnycha Encyklopediya. Donbass, Donetsk 2004.

[4] Steudel A., Batenburg L., Fischer H. et al.: Appl. Clay Sci., 2009, 44, 105.

[5] Muhlenov I., Dobkina E., Deryuzhkyna V. and Soroko V.: Tekhnologiya Katalizatorov. Khimiya, Leningrad 1989.

[6] Frini-Srasra N and Srasra E.: Desalination, 2010, 250, 26.

[7] Yurkselen Y. and Kaya A.: Eng. Geol., 2008, 102, 38.

[8] Wang Y., Du B., Dou X. et al.: Colloids \& Surf. A, 2007, 307, 16.

[9] Prélot B., Lantenois S., Nedellec Y. et al.: Colloids \& and Surf. A, 2010, 355, 67.

[10] Stumm W.: Chemistry of the Solid-Water Interface. WileyInterscience, New York 1992.

[11] Langmuir D.: Aqueous Environmental Geochemistry. Prentice Hall, Upper Saddle River, New Jersey 1997.

[12] Neter J., Wasserman W. and Kutner M.: Applied Linear Statistical Models: Regression, Analysis of Variance, and Experimental Designs. Irwin, Homewood, Illinois 1985.

\section{АКТИВОВАНИЙ ПАЛИГОРСЬКІТ ТА АКТИВОВАНА БЕНТОНІТОВА ГЛИНА ЯК КАТАЛІЗАТОРИ ПРОЦЕСУ ОТРИМАННЯ КООЛІГОМЕРІВ ІЗ ПОБІЧНИХ ПРОДУКТІВ ЕТИЛЕНОВИХ ВИРОБНИЦТВ}

\begin{abstract}
Анотація. Досліджено отримання коолігомерів із фракиії $C_{9}$ рідких продуктів піролізу дизельного палива в присутності алюмосилікатних каталізаторів кислотного типу: активованого палигорськіту та активованої бентонітовоі глини. Вивчено залежність виходу та властивостей коолігомеру від умов процесу. Досліджено властивості каталізаторів. Проаналізовано зв'язок між властивостями каталізаторів та результатами, отриманими в їх присутності. Здійснено порівняльний аналіз каталізаторів.
\end{abstract}

Ключові слова: рідкі продукти піролізу, коолігомери, гетерогенні каталізатори, палигорськіт, бентонітова глина. 